\title{
Trends in list prices, net prices, and discounts of self-administered injectable tumor necrosis factor inhibitors
}

\author{
Alvaro San-Juan-Rodriguez, PharmD; Vincent M Piro, BS; Chester B Good, MD, MPH; \\ Walid F Gellad, MD, MPH; and Inmaculada Hernandez, PharmD, PhD
}

\section{What is already known about this subject}

- On average, list prices of tumor necrosis factor (TNF) inhibitors increased by $144 \%$ from 2009 to 2016 ; these increases can hinder patient access to these essential medications and negatively affect health outcomes.

- Recent evidence suggests that half of the list price increases in the TNF inhibitor category were offset by rising manufacturer discounts.

- It remains unclear to what extent manufacturers' discounts have offset increases in list prices of each TNF inhibitor, so evaluating trends in net prices and discounts at the product level will be paramount in understanding the role of competition in the biologic market.

\section{What this study adds}

- Rising manufacturer discounts offset $47 \%$ of the increases in list prices of etanercept, $45 \%$ for adalimumab, $58 \%$ for golimumab, and $59 \%$ for certolizumab.

- After accounting for the increases in manufacturer discounts, net prices in 2007-2019 grew at a mean annual rate of $10.7 \%$ for etanercept, $9.9 \%$ for adalimumab, $8.7 \%$ for golimumab, and $9.2 \%$ for certolizumab.

- Despite growing manufacturer discounts, net prices of each selfadministered injectable TNF inhibitor still increased by nearly $10 \%$ in 2007 2019, leading to net prices tripling for adalimumab and more than doubling for etanercept, golimumab, and certolizumab.

\author{
Author affiliations \\ Alvaro San-Juan-Rodriguez, PharmD, and \\ Immaculada Hernandez, PharmD, PhD, \\ Department of Pharmacy and Therapeutics, \\ School of Pharmacy, University of Pittsburgh, \\ Pittsburgh, PA. Vincent M Piro, BS, \\ Department of Pharmacy and Therapeutics, \\ School of Pharmacy, University of Pittsburgh, \\ Pittsburgh, PA, and Insurance Services \\ Division, UPMC Health Plan, Pittsburgh, PA. \\ Chester B Good, MD, MPH, Insurance \\ Services Division, UPMC Health Plan, \\ Pittsburgh, PA, and Walid F Gellad, MD, \\ $\mathrm{MPH}$, Division of General Internal Medicine, \\ School of Medicine, University of Pittsburgh, \\ Pittsburgh, PA.
}

AUTHOR CORRESPONDENCE: Alvaro San-Juan-Rodriguez, 412.378.2940; als440@pitt.edu

J Manag Care Spec Pharm. 2021;27(1):112-17

Copyright $(2021$, Academy of Managed Care Pharmacy. All rights reserved.

and golimumab from the investment firm SSR Health, which uses company-reported sales to estimate net prices and discounts for brand products manufactured by publicly traded companies. For each drug and year, we calculated annual costs of treatment for patients with rheumatoid arthritis based on list and net prices and discounts in Medicaid and other payers.

RESULTS: From 2007-2019, list prices of etanercept and adalimumab increased by $293 \%$ 
and $295 \%$, respectively; however, discounts offset $47 \%$ and $45 \%$ of these increases, leading to net price increases of $171 \%$ and $203 \%$. List prices of golimumab and certolizumab increased by $183 \%$ and $182 \%$, respectively, but with discounts offsetting $58 \%$ and $59 \%$ of these increases, net prices increased by $103 \%$ and $109 \%$. Net prices of golimumab started to decrease after 2016, while net prices of adalimumab and certolizumab experienced their first drop in 2019. Across the study period, discounts in Medicaid and in other payers increased, respectively, from $21 \%$ to $85 \%$ and $6 \%$ to $32 \%$ for etanercept; from $26 \%$ to $88 \%$ and $19 \%$ to $35 \%$ for adalimumab; from $28 \%$ to $63 \%$ and $22 \%$ to $46 \%$ for golimumab; and from $29 \%$ to $83 \%$ and $27 \%$ to $47 \%$ for certolizumab.

CONCLUSIONS: Despite growing manufacturer discounts, net prices of self-administered injectable TNF inhibitors still increased at a mean annual rate of $9.6 \%$ in 2007-2019. This led to net prices tripling for adalimumab and more than doubling for etanercept, golimumab, and certolizumab.

List prices of tumor necrosis factor (TNF) inhibitors have increased drastically during the last decade. ${ }^{1}$ Because of their high and rising prices and their widespread use, these agents represent a large and growing segment of pharmaceutical spending in the United States. ${ }^{2}$ Increases in list prices of TNF inhibitors are worrisome because they can hinder patient affordability and access to these essential medications, particularly in uninsured and underinsured populations. $^{3}$

There are 4 self-administered injectable TNF inhibitors available in the U.S. market-all brand drugs. The older agents-etanercept and adalimumab-were approved by the U.S. Food and Drug Administration (FDA) for the treatment of rheumatoid arthritis (RA) in 1998 and 2002, respectively. In 2009, golimumab and certolizumab were approved. Previous research found that the entry of brand competition into the TNF inhibitor market led to even faster list price growth of existing agents. ${ }^{1}$

However, increases in list prices may reflect competition in the discount space rather than increases in net prices. In fact, a recent study showed that, across TNF inhibitor categories, increases in discounts offset half of the increases in list prices in 2007-2018. ${ }^{4}$ Notwithstanding, it remains unclear to what extent manufacturers' discounts have offset increases in list prices of each individual product within the category and by how much net prices increased after accounting for these discounts. Analyses evaluating product-level trends in net prices and discounts will be paramount in understanding the role of competition in the biologic market.
The objectives of this study were to (a) describe productlevel changes in net prices for each self-administered injectable TNF inhibitor in 2007-2019 and (b) quantify to what extent list price increases have been offset by manufacturer discounts.

\section{Methods}

\section{STUDY SAMPLE}

The study sample included all self-administered injectable TNF inhibitors approved by the FDA for the treatment of RA, ${ }^{1}$ including etanercept (Enbrel; approved in November 1998), adalimumab (Humira; approved in December 2002), golimumab (Simponi; approved in April 2009), and certolizumab (Cimzia; approved in May 2009).

\section{DATA SOURCE}

We obtained pricing and discount data from the investment firm SSR Health. ${ }^{5}$ This dataset, which has been used in previous peer-review research, ${ }^{4,6-8}$ contains quarterly estimates of list prices, net prices, and discounts for brand prescription drugs with U.S. sales reported by publicly traded pharmaceutical manufacturers. These exclude drugs manufactured by private companies, such as Purdue Pharma or Boehringer Ingelheim. SSR Health separately estimates discounts for Medicaid and for all other payers.

For each product and quarter, the investment firm estimates the net price per unit as company-reported net sales divided by the number of units sold in the United States, obtained from Symphony Health. ${ }^{9}$ This dataset contains the number of units sold for each product in retail pharmacy, inpatient, and other clinical settings. Symphony Health samples over 5,000 hospitals and 840,000 practitioner suites and captures 93\% of the prescriptions dispensed across the United States.

Estimates of net price reflect the average manufacturer revenue for each drug after accounting for all concessions to purchasers, including rebates, prompt pay discounts, volume discounts, coupon cards, and any other concessions accounted for by manufacturers in the reporting of sales. ${ }^{5}$ In other words, estimates of net price represent average net sale prices from manufacturers to purchasers. Importantly, these estimates of net prices do not reflect what any specific payers or patients pay. ${ }^{4}$

Discounts are then estimated as (list price-net price)/list price. ${ }^{5}$ In order to provide separated discounts for Medicaid and for payers other than Medicaid, SSR Health calculates the Medicaid unit rebate amount, for each drug and quarter, as the sum of (a) the basic rebate $(23.1 \%$ of average manufacturer price for brand drugs) and (b) the inflation rebate for price increases above the Consumer Price Index. ${ }^{10}$ Total 


\begin{tabular}{|c|c|c|c|c|}
\hline & Etanercept & Adalimumab & Golimumab & Certolizumab \\
\hline \multicolumn{5}{|l|}{ List price } \\
\hline Initial annual cost of treatment, \$ (year) & $17,364(2007)$ & 17,689 (2007) & $20,358 \quad(2010)$ & $22,992(2010)$ \\
\hline Final annual cost of treatment, \$ (year) & 68,277 (2019) & $69,850(2019)$ & $57,610(2019)$ & 64,911 (2019) \\
\hline Relative change, $\%$ & 293.2 & 294.9 & 183.0 & 182.3 \\
\hline Mean annual change, $\%$ & 12.2 & 12.3 & 12.3 & 12.3 \\
\hline \multicolumn{5}{|l|}{ Net price } \\
\hline Initial annual cost of treatment, \$ (year) & $15,951(2007)$ & $14,242(2007)$ & $15,243 \quad(2010)$ & $15,828(2010)$ \\
\hline Final annual cost of treatment, $\$$ (year) & $43,148 \quad(2019)$ & $43,088 \quad(2019)$ & 30,939 (2019) & $33,146 \quad(2019)$ \\
\hline Relative change, $\%$ & 170.5 & 202.5 & 103.0 & 109.4 \\
\hline Mean annual change, \% & 10.7 & 9.9 & 8.7 & 9.2 \\
\hline$\%$ of list price increase offset by discounts & 46.6 & 44.7 & 57.9 & 58.7 \\
\hline \multicolumn{5}{|c|}{$\begin{array}{l}\text { Notes: This table shows list and net estimates of the annual cost of treatment for etanercept, adalimumab, golimumab, and certolizumab in the first and last } \\
\text { year of inclusion in our study period. Additionally, for each product, the table depicts the relative changes in annual costs of treatment across the study period, } \\
\text { calculated as (final cost-initial cost)/(initial cost); the mean annual change, calculated as the mean year-over-year percent price change over the study period; } \\
\text { and the percentage of list price increases offset by discounts, calculated as the difference between the absolute change (i.e., final cost-initial cost) in list and net } \\
\text { prices divided by the absolute change in list prices. We defined annual cost of treatment based on FDA dosing recommendations as the mean cost for treating a } \\
\text { standard patient with rheumatoid arthritis for a year. Net prices capture all manufacturer concessions including rebates, prompt pay discounts, volume discounts } \\
\text { copay cards, and any other concessions accounted for in the reporting of net sales. We excluded price observations in } 2009 \text { for golimumab and certolizumab due } \\
\text { to data instability introduced by inventory variability of these drugs in their launch year. All price estimates are expressed in nominal dollars. } \\
\text { FDA=U.S. Food and Drug Administration. }\end{array}$} \\
\hline
\end{tabular}

discounts to Medicaid are estimated as the product of the Medicaid unit rebate amount and the number of units sold to Medicaid that quarter, obtained from Medicaid state drug utilization reports. ${ }^{5}$ Discounts to payers other than Medicaid are calculated as the difference between the total discounts and discounts to Medicaid. Finally, the discount per unit for payers other than Medicaid for each drug and quarter is estimated by dividing total discounts for payers other than Medicaid by the number of units sold to payers other than Medicaid. Because of this methodology, supplemental Medicaid rebates negotiated by states or managed care organizations and any Medicaid discount derived from best price provisions are not captured by estimates of Medicaid discounts, but instead are captured by estimates of discounts for payers other than Medicaid.

Estimates of net prices and discounts can be subject to discrepancies between the actual number of units sold by a manufacturer in a given quarter and the number of units sold by retail pharmacies and nonretail institutions captured by Symphony Health in that same quarter. This can lead to estimates of net prices greater than list prices. In order to address this issue, we excluded quarterly records when the net price was greater than list price. This methodology has been used and validated previously.

\section{OUTCOMES}

Our study included 4 outcomes: list price, net price, discount for Medicaid, and discount for payers other than Medicaid. All outcomes were estimated for each year in the study period as the mean across 4 quarters. List prices were estimated using wholesale acquisition costs and reflect manufacturers' prices to wholesalers or direct purchasers but do not capture any discounts. Net prices reflect the average revenue accrued by manufacturers after concessions. Discounts capture all manufacturer concessions, not solely rebates.

We expressed estimates of list and net prices as annual cost of treatment for patients with RA in nominal dollars. We used the FDA-approved recommended dosing to calculate the number of units needed for an annual course of treatment with each product for a standard RA patient and multiplied it by SSR Health estimates of list and net prices per unit.

\section{ANALYSES}

For each product, we calculated absolute and relative changes in list and net annual costs of treatment across the study period. For instance, if a product's annual cost of treatment increased from $\$ 10,000$ in 2007 to $\$ 20,000$ in 2019 , its absolute change in 2007-2019 would be $\$ 10,000$, 


\section{FIGURE 1 Trends in List and Net Prices of Self-Administered TNF Inhibitors, 2007-2019}

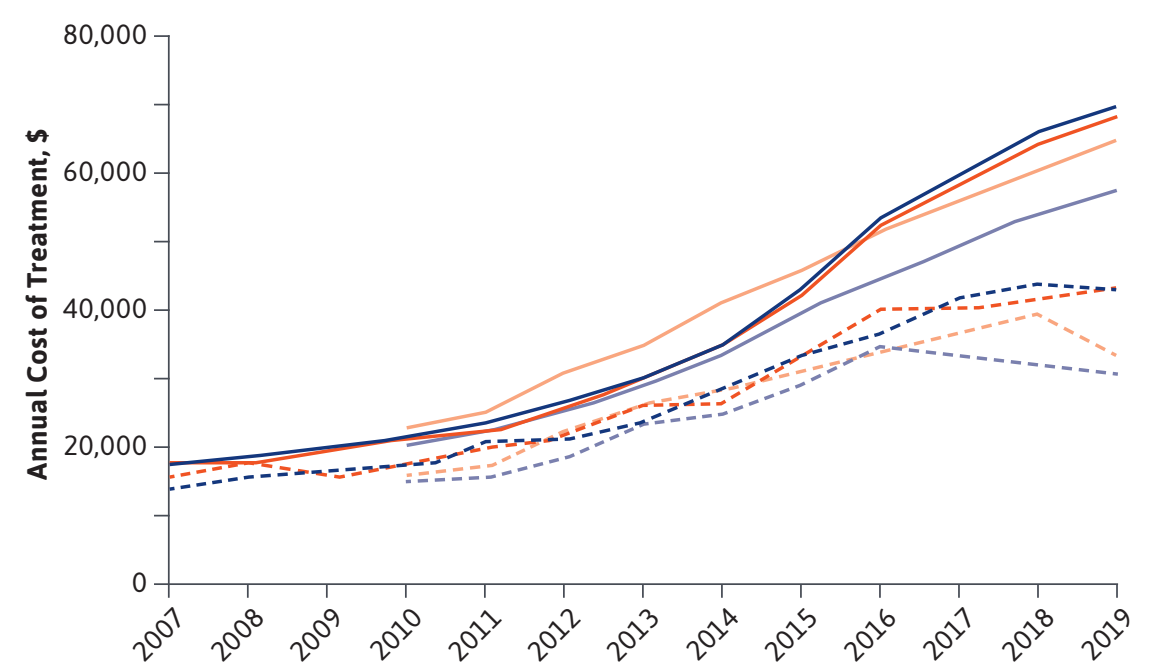

- Adalimumab list price

---- Adalimumab net price

Etanercapt list price

- - - - Etanercapt net price

_ Golimumab list price

---- Golimumab net price

_ Certolizumab list price

$=-==$ Certolizumab net price

Notes: This figure shows trends in list and net prices of adalimumab, etanercept, golimumab, and certolizumab. We defined annual cost of treatment based on the U.S. Food and Drug Administration dosing recommendations as the mean price of treating a standard patient with rheumatoid arthritis for a year. We excluded price observations in 2009 for golimumab and certolizumab due to data instability introduced by inventory variability of these drugs in their launch year. All price estimates are expressed in nominal dollars.

FDA =U.S. Food and Drug Administration; TNF=tumor necrosis factor.

while its relative change would be of $100 \%$. We further calculated the percentage of list price increases offset by discounts for each product as the difference between the absolute change in list and net prices divided by the absolute change in list prices. For instance, if the list price of a drug increased by $\$ 10,000$ (from $\$ 10,000$ in 2007 to $\$ 20,000$ in 2019 ) and the net price by $\$ 5,000$ (from $\$ 8,000$ to $\$ 13,000$ ), then $50 \%$ of the increase in list price was offset by discounts ( $[\$ 10,000-\$ 5,000] / \$ 10,000=50 \%)$.

All analyses used statistical software SAS version 9.4 (SAS Institute, Cary, NC).

\section{Results}

Across the study period, list prices of all self-administered injectable TNF inhibitors increased at a mean annual rate of 12.3\% (Table 1), following parallel price trajectories (Figure 1). However, manufacturer discounts offset a mean of $52 \%$ of these increases. Despite this, net prices still increased at a mean annual rate of $9.6 \%$.

For etanercept, list price increased by $293 \%$, from an annual cost of treatment of $\$ 17,364$ in 2007 to $\$ 68,277$ in 2019 (Figure 1). Discounts offset $47 \%$ of list price increases, leading to a $171 \%$ increase in the annual net price of treatment, from $\$ 15,951$ in 2007 to $\$ 43,148$ in 2019 . Across the study period, etanercept discounts increased from $21 \%$ to $85 \%$ for Medicaid and from $6 \%$ to $32 \%$ for payers other than Medicaid (Supplementary Figure 1, available in online article).

For adalimumab, list price increased by $295 \%$, from an annual cost of treatment of $\$ 17,689$ in 2007 to $\$ 69,850$ in 2019 (Figure 1). Annual net price of treatment increased by $210 \%$, from $\$ 14,242$ in 2007 to $\$ 44,174$ in 2018 and decreased by $3 \%$ in 2019 down to $\$ 43,088$. Across the study period, adalimumab discounts offset $45 \%$ of list price increases, rising from $26 \%$ to $88 \%$ for Medicaid and from $19 \%$ to $35 \%$ for payers other than Medicaid (Supplementary Figure 1).

For golimumab, list price increased by $183 \%$, from an annual cost of treatment of $\$ 20,358$ in 2010 to $\$ 57,610$ in 2019 (Figure 1). Annual net price of treatment increased by $128 \%$, from $\$ 15,243$ in 2010 to $\$ 34,771$ in 2016 , and decreased by $11 \%$ in $2017-2019$ down to $\$ 30,940$. Across the study period, golimumab discounts offset $58 \%$ of list price increases, rising from $28 \%$ to $63 \%$ for Medicaid and from $22 \%$ to $46 \%$ for payers other than Medicaid (Supplementary Figure 1).

For certolizumab, list price increased by $182 \%$, from an annual cost of treatment of $\$ 22,922$ in 2010 to $\$ 64,911$ in 2019 (Figure 1). Annual net price of treatment increased by $149 \%$ from $\$ 15,828$ in 2010 to $\$ 39,454$ in 2018 and decreased by $16 \%$ in 2019 , down to $\$ 33,146$. Across the study period, 
certolizumab discounts offset $59 \%$ of list price increases, rising from $29 \%$ to $83 \%$ for Medicaid and from $27 \%$ to $47 \%$ for payers other than Medicaid (Supplementary Figure 1).

\section{Discussion}

To the best of our knowledge, this study is the first to evaluate product-level changes in list prices, net prices, and discounts of each available self-administered injectable TNF inhibitor from 2007-2019. We found that, from 20072019 , list prices increased at a mean annual rate of $12.3 \%$. However, growing manufacturer discounts offset $52 \%$ of these increases. After accounting for the increases in manufacturer discounts, net prices still increased at a mean annual rate of $9.6 \%$ in 2007-2019, outpacing general inflation by 5.2 -fold, which increased at a mean annual rate of $1.8 \%$ over the same period. This led to net prices tripling for adalimumab over the study period and more than doubling for etanercept, golimumab, and certolizumab. Increases in net prices are especially concerning because, with more than $\$ 20.6$ billion in U.S. net sales in $2018,{ }^{5}$ self-administered injectable TNF inhibitors have a major effect on pharmaceutical spending across all payers. ${ }^{11}$

These results are consistent with our previous work, ${ }^{4}$ where we evaluated trends in list prices, net prices, and discounts for all brand medications with U.S. sales reported by publicly traded companies. In our previous analysis, we found large list price increases across the U.S. brand prescription drug market. Nevertheless, increases in discounts offset, on average, $62 \%$ of these list prices increases, but with a wide variation across drug categories. Our previous work assessed trends in the overall TNF inhibitor category, finding that $56 \%$ of list price increases had been offset by discounts; however, it did not assess individual productlevel trends. In addition, it did not include golimumab, one of the newer agents, or data from 2019, which shows drops in net prices for all products except etanercept.

Evaluating trends at the product level, as opposed to the category level, is important because it enables us to discern among distinct pricing strategies pursued by different manufacturers. For instance, similar gross costs of treatment over time for all products and varying levels of discounts supports the premise that competition in the pharmaceutical market does not occur at the list price but rather in the discount space. ${ }^{4}$ Despite growing manufacturer discounts, net prices increased in parallel until 2016. Divergences in net price trends started in 2016, when golimumab net price began to decrease and etanercept net price growth slowed, while the net prices of adalimumab and certolizumab continued to increase. It was not until 2019 that net prices of adalimumab and certolizumab dropped.
This recent stabilization and even reduction in net prices are likely explained by a combination of factors. Manufacturers of mechanistically similar drugs, such as TNF inhibitors, compete for the inclusion and placement in insurers' formularies by offering greater rebates over time. Manufacturers also compete through the provision of copay coupons and other programs that offset patients' out-ofpocket costs. On the insurance side, the increased uptake of copay accumulators and maximizers may have also contributed to the observed net price reductions. Additionally, the recent approval in late 2016 and mid 2017 of 2 biosimilars of infliximab, ${ }^{11}$ a provider-administered TNF inhibitor, may have increased competition between the self-administered and provider-administered categories, contributing to the trends observed in the self-administered category. Finally, recent net price reductions experienced by most selfadministered injectable TNF inhibitors may also respond to the increased public scrutiny of high and rising list prices of prescription drugs. ${ }^{6}$

Discounts for self-administered injectable TNF inhibitors increased substantially in 2007-2019, in particular for Medicaid, whose discounts increased by a mean of 44 percentage points. These large increases observed in Medicaid discounts are a product of the statutory inflation rebate, which penalizes increases in list prices above inflation. Still, discounts for other payers increased by a mean of 22 percentage points over the observation period. Yet, manufacturer discounts are not generally passed on to patients, whose coinsurances are paid based on list, not net, prices except for copay coupons (which are not applicable to Medicare patients due to the anti-kickback statute). Thus, drastic list price growth has a profound effect on the financial burden of patients and further exacerbates disparities in access to medications for underinsured and uninsured patients.

Despite the evidence of increasing manufacturer discounts, net prices of self-administered injectable TNF inhibitors still increased dramatically in 2007-2019, outpacing general inflation by far. A potential factor partially explaining these substantial net price increases could be the absence of within-molecule competition in this category. Remarkably, although etanercept and adalimumab have been on the market for more than 17 years, and even when 2 biosimilars for etanercept and 4 for adalimumab have been approved by the FDA, no biosimilar competitors have reached the market. This represents a market failure derived from common manufacturer practices that effectively block the entry of biosimilars, such as patent evergreening, patent litigation, and pay-for-delay agreements. However, the entry of biosimilars in the self-administered injectable TNF inhibitor market would likely foster competition. 
Facilitating the launch of biosimilars is particularly important, given the recent evidence that suggests that the entry of the few biosimilars present in the U.S. drug market achieved substantial net price decreases of their originator biologics. ${ }^{6}$

\section{LIMITATIONS}

Our study is subject to 4 main limitations. First, our analyses only include self-administered injectable TNF inhibitors and does not include oral or physician-administered products indicated for RA. Physician-administered products were excluded because they are covered under the medical benefit and not generally subject to formulary management and associated discounting practices.

Second, since our estimates of discounts include all manufacturer concessions to purchasers, our analysis cannot determine whether discount growth was driven by increases in rebates or to other manufacturer concessions, such as copay cards.

Third, SSR Health estimates Medicaid discounts as the statutory rebates $(23.1 \%+$ inflation rebate) and then assigns any other discounts to payers other than Medicaid. As a result, supplemental Medicaid rebates and Medicaid discounts derived from best price provisions were not captured by our estimates of discounts in Medicaid. Thus, we likely underestimated discounts in Medicaid and overestimated discounts to payers other than Medicaid.

Finally, we excluded price and discount observations in 2009 for golimumab and certolizumab because of data instability introduced by inventory variability of these drugs in their launch year.

\section{Conclusions}

Despite growing manufacturer discounts, net prices of self-administered injectable TNF inhibitors still increased at a mean annual rate of $9.6 \%$ in $2007-$ 2019. This led to net prices tripling for adalimumab and more than doubling for etanercept, golimumab, and certolizumab.

\section{DISCLOSURES}

This study was funded by the Myers Family Foundation. Hernandez is funded by the National Heart, Lung and Blood Institute (grant number K01HL142847). Funding sources had no role in design and conduct of the study; collection, management, analysis, and interpretation of the data; preparation, review, or approval of the manuscript; or decision to submit the manuscript for publication. Hernandez has served on Pfizer's scientific advisory board. The other authors have nothing to disclose.

\section{REFERENCES}

1. San-Juan-Rodriguez A, Prokopovich MV, Shrank WH, Good CB, Hernandez I. Assessment of price changes of existing tumor necrosis factor inhibitors after the market entry of competitors. JAMA Intern Med. 2019;179(5):713-16.

2. Gellad WF, Good CB. Adalimumab and the challenges for biosimilars. JAMA. October 23, 2019. Online ahead of print. doi: 10.1001/jama.2019.16275

3. Kim H, Alten R, Avedano L, et al. The future of biosimilars: maximizing benefits across immune-mediated inflammatory diseases. Drugs. 2020;80(2):99-113.

4. Hernandez I, San-Juan-Rodriguez A, Good CB, Gellad WF. Changes in list prices, net prices, and discounts for branded drugs in the U.S., 2007-2018. JAMA. 2020;323(9):854-62.
5. SSR Health. US prescription brand net pricing data. 2019. Accessed November 28, 2020. https://www.ssrhealth.com

6. Feldman WB, Rome BN, Lehmann LS, Kesselheim AS. Estimation of Medicare Part D spending on insulin for patients with diabetes using negotiated prices and a defined formulary. JAMA Intern Med. 2020;180(4):597-601.

7. San-Juan-Rodriguez A, Gellad WF, Good CB, Hernandez I. Trends in list prices, net prices, and discounts for originator biologics facing biosimilar competition. JAMA Netw Open. 2019;2(12):e1917379.

8. Wineinger NE, Zhang Y, Topol EJ. Trends in prices of popular brand-name prescription drugs in the United States. JAMA Netw Open. 2019;2(5):e194791.

9. Symphony Health. Symphony Health website. Accessed November 28, 2020. https://symphonyhealth.prahs.com

10. Centers for Medicare \& Medicaid Services. Unit rebate amount calculation for single source or innovator multiple source drugs. Accessed November 28, 2020. https://www. medicaid.gov/medicaid/prescriptiondrugs/medicaid-drug-rebate-program/ unit-rebate-calculation/unit-rebateamount-calculation-for-single-sourceor-innovator-multiple-source-drugs/ index.html.

11. Express Scripts. 2018 drug trend report. 2019. Accessed November 28, 2020. https://corporate-site-labs-prod. s3.us-east-2.amazonaws.com/2020-02/ Express\%20Scripts\%202018\%20Drug\%20 Trend\%20Report.pdf 